\title{
Cervical Cancer Screening Among Marginalized Women: A Cross-Sectional Intervention Study
}

\author{
Thomas HG Bongaerts $\mathbb{D}^{1, *}$ \\ Marlieke Ridder ${ }^{1,2, *}$ \\ Josephina CJ Vermeer- \\ Mens (iD) ${ }^{3}$ \\ Jeanette J Plukkel ${ }^{2}$ \\ Mattijs E Numans (D) \\ Frederike L Büchner (D) \\ 'Leiden University Medical Center \\ LUMC-Campus the Hague, Department \\ of Public Health and Primary Care, The \\ Hague, the Netherlands; ${ }^{2}$ Municipal \\ Health Service Rotterdam-Rijnmond, \\ Rotterdam, the Netherlands; ${ }^{3}$ Erasmus \\ Medical Center, Department of \\ Pathology, Rotterdam, the Netherlands \\ *These authors contributed equally to \\ this work
}

Background: Many countries organize population-based cervical cancer screening programs (CSP). In the Netherlands, eligible women are invited by mail. Marginalized women living in unstable conditions and homeless women often fail to receive the invitation letter. These women also experience access barriers to regular healthcare. Consequently, despite presumably being at higher risk of developing cervical cancer due to prevalent risk factors, marginalized women are rarely screened for cervical cancer. The aim of the study was to identify the prevalence of (pre)cancerous abnormalities among marginalized women, and subsequently explore invitation approaches to enhance their screening participation.

Methods: A cross-sectional intervention study was conducted in Rotterdam, the Netherlands. Between February and May 2019, marginalized women aged 20-60 years were invited to participate in cervical screening. A participant was considered screenpositive when they tested positive for high-risk human papilloma virus (HR-HPV) and showed cytological abnormalities. Data of the study population were compared with regional data of the Dutch CSP. Various invitation approaches were used to recruit women.

Results: Out of 74 included women, 12 participants (16\%) were found screen-positive, against $3.4 \%$ in women screened by the Dutch CSP. The prevalence ratio for the study population was 4.4 (95\% CI 1.9-8.6) compared with women screened by the Dutch CSP Using a direct, pro-active approach resulted in participation of $92 \%$ of the included women. Conclusion: Marginalized women have an increased risk of (pre)cancerous cervical abnormalities in screening, compared with women screened by the Dutch CSP. A direct proactive approach was the most effective to stimulate screening participation. Enhancement of screening uptake for this population needs special effort.

Keywords: cervical cancer, screening participation, marginalized women, Netherlands

\section{Introduction}

Cervical cancer is the fourth most common cancer in women worldwide. ${ }^{1}$ The main cause of cervical cancer is a chronic infection with high-risk human papillomavirus (HR-HPV). Although around $80 \%$ of the women get infected with this virus, only $1 \%$ of the infected women develop cervical cancer. ${ }^{2}$ Risk factors for a chronic HRHPV infection are smoking, a history of chlamydia, herpes, (a history of having) multiple sexual partners, an early sexarche and immune system deficiencies. ${ }^{3}$ Mortality from cervical cancer is preventable when detected and treated in an early or precursor stage. Therefore, many countries organize a national cervical cancer screening program (CSP), for early diagnosis.

In the Netherlands, all women between 30 and 60 years of age are invited to participate in the regionally coordinated national CSP every 5 years. Invitation is
Correspondence: Thomas HG Bongaerts LUMC-Campus the Hague, Department of Public Health and Primary Care, Leiden University Medical Center, Turfmarkt 99,

The Hague, 25II DV, the Netherlands

Tel +31708009047

Email t.h.g.bongaerts@lumc.nl 
by mail, sent to a registered home address. Attendance is voluntary and the primary screening test is free of charge. Women are invited to make an appointment with their general practitioner (GP) for having a cervical smear, or (since 2017) can order a selfsampling HR-HPV-test. Analysis is stepped and starts with an HR-HPV test. In case of a positive test for HRHPV, a subsequent cytological analysis will be performed. ${ }^{4}$ In $201857.6 \%$ of all eligible women participated in the Dutch cervical CSP. ${ }^{5}$ Despite the availability of a CSP, half of all women who developed cervical cancer were never or insufficiently screened. ${ }^{6}$ In the Netherlands, characteristics correlating with low screening uptake are as follows: being born outside the Netherlands, living in an urban region, low socioeconomic status (SES), and a younger age. ${ }^{3,7}$

Sex workers living in unstable conditions, homeless women and undocumented women - from now on referred as marginalized women - share those characteristics and are often not registered with the municipality, lack a permanent address, or are not registered at all. Therefore, they often fail to receive the invitation letters, or are not invited at all. Moreover, these women face various access barriers to regular healthcare, and they are confronted with other priorities than partaking in preventive services. ${ }^{8-10}$ Prior studies have showed how hard it can be to engage marginalized women in screening programs. Even after removing healthcare and financial barriers, $38 \%$ of the homeless women would still decline a cervical screening smear. ${ }^{11}$ Marginalized women often face multiple risk factors for a chronic HR-HPV infection and consequently, for cervical cancer. A study in the United States of America (US) showed a 4.4 times higher incidence of cervical cancer in homeless women, compared with the average female population, making cervical cancer the third most common type of cancer in this specific population. ${ }^{12}$

There have been several studies on cervical cancer and screening including marginalized women in the US. ${ }^{11,12}$ However, to our knowledge, European studies are lacking. Due to the differences between the US and Europe in population, organization of care, and screening for marginalized populations, there is a need for European input on this subject. ${ }^{8}$ The study had two specific aims. The first was to identify the prevalence of (pre)cancerous abnormalities among marginalized women. The second was to explore invitation appraoches to enhance the screening uptake among this specific group of women in an urban setting in the Netherlands.

\section{Methods}

A cross-sectional intervention study among marginalized women was performed in Rotterdam, the Netherlands. Rotterdam is the second largest city of the Netherlands. The study was conducted between February 2019 and June 2019. The study population consisted of women in unstable living conditions, concerning: sex workers, homeless women, uninsured women (in the Netherlands, health insurance is obligatory by law; only a small minority is uninsured, mostly due to the lack of a home address), and undocumented women (women without a residency status). The inclusion criteria were as follows: female sex, age 20-60 years, and the absence of a registered address at a given point in the last 5 years. Exclusion criteria were as follows: having had a cervical smear in the preceding year, not having a cervix, being incapacitated, being pregnant, having a menstrual period at that specific moment, and having the option to access regular healthcare abroad.

Recruitment of the women took place at homeless shelters, day and night shelters for undocumented people, respite care locations, safe houses for sexual trafficking victims, in brothels and sex worker walk-in houses. The cervical smears were performed by a medical team consisting of a female streetdoctor and a female nurse familiar with the study population. Topics such as contraceptives, sexual trauma and sexual health are part of the expertise of this medical team.

Depending on the local options, either a direct or indirect invitation approach was used for recruiting the women. The direct invitation approach contained a proactive offer of an immediate cervical smear. This was done during the consultation hours of the streetdoctor or combined with the consultations for sexual transmitted infections (STIs) by sexual health workers. The indirect approach consisted of distributing posters in relevant areas and announcements on a website, with information about the opportunity to have a cervical smear performed. Furthermore, mails were sent to all known care providers or case managers of the population under study, with the option to make an appointment for their client to have a cervical smear.

The screening method used was liquid-based cytology sampling. The samples were analyzed using both a HRHPV test (COBAS $6800^{\circledR}$ HR-HPV, Roche) and cytology (ThinPrep ${ }^{\circledR}$ PAP-test, examined with computer assisted 
screening on the ThinPrep ${ }^{\circledR}$ Integrated Imager by Hologic) on each sample. The Dutch CSP uses the same laboratory methods. ${ }^{5}$ In the Netherlands, the Papanicolaou (Pap) classification is used to score the test outcome. A participant was considered being a screen-positive, when they tested positive for high-risk human papilloma virus (HR-HPV) and showed cytological abnormalities ( $\geq$ Pap-2). This corresponds with the National Health Service Cervical Screening Program of the United Kingdom as $\geq \mathrm{HR}-\mathrm{HPV}$ positive and borderline changes in the squamous/endocervical cells, and with the American Bethesda-classification as $\geq$ atypical squamous cells of uncertain significance. $^{13,14}$

Participants were informed of their test results by means of consultations, text messages and phone calls; usually directly to the participant, but occasionally to their care providers. Referral to a gynecologist was done by the streetdoctor, or if present, the own GP. A public health safety-net team served as backup, whenever women needed to be located for follow-up but did not show at their appointment.

\section{Data Management}

The medical team registered details of the procedure in the routine medical files of the participant. At inclusion, the women gave consent to share their medical record for research. For data-extraction, data were anonymized by coding all study participants and removing all information that would enable researchers to trace back the data to a single individual. HRHPV status and cytological classifications were translated into binary outcomes, respectively negative/positive and normal/ abnormal smear. Age (in years) and the inclusion location were extracted as well. The inclusion method was coded as indirect or as direct. Anecdotal reasons for refusal to participate in the study were registered for the few women who declined participation and were willing to the reason. Data were stored and saved in compliance with guidelines of Good Research Practices. Upfront, this study was approved by the Ethics Committee of the Leiden University Medical Centre and was conducted in accordance with the Declaration of Helsinki.

\section{Power Analysis}

The Dutch CSP is coordinated by five regional screening organizations, making screening data available and insightful on specific regions. "Stichting Bevolkingsonderzoek Zuid-West" is the designated screening organization for Rotterdam concerned with the southwest region of the Netherlands. Of all participating women in the southwest region $3.4 \%$ were found to be screen-positive in $2018 .^{15}$ A prior study on homeless women presented a percentage of $18 \%$ screen-positive women. ${ }^{11}$ Using this information, a power analysis was performed on Clincalc.com to determine the size needed for the study population in order to detect a relevant difference in outcome. ${ }^{16}$ Using the anticipated incidence of $18 \%$ resulted in a needed sample size of $\mathrm{n}=22(\alpha=0.05, \beta=0.2)$. When lowering the adjusted rate to a safer prediction and expecting an outcome of $12 \%$, the needed sample size was set at $\mathrm{n}=53(\alpha=0.05, \beta=0.2)$.

\section{Data Analysis}

The prevalence of screen-positive women from the study compared with the prevalence rates of the last available regional data from the Dutch CSP in 2018. ${ }^{15,17}$ Data were analyzed descriptively using counts (percentages), prevalence rates and prevalence ratios (PRs). The prevalence ratios and their confidence intervals (CIs) were calculated by performing binomial tests. The null hypothesis was that the prevalence rate of screen-positive marginalized women, is equal to the prevalence rate of women screened by the Dutch cervical CSP. In Tables 1 and 2 the data are subdivided per age cohorts of 5 years, comparable to the 5 -yearly screening.

In order to provide the PR, a calculation was performed excluding and including the women under the age of 30 . Additionally, screen-positive women were compared on the basis of their legal-status (undocumented versus documented). For both PR calculations, the regional prevalence rates of screen-positive women by the Dutch CSP were used. These rates are displayed in the Supplementary Table.

To evaluate the various invitation approaches, the number of included participants per approach were counted. All analyses were conducted using IBM SPSS Statistics 25.

\section{Results}

In total, 74 women were included in the study, with a mean age of 38.2 years (SD 10.4 years). Out of 74 participants, 12 (16\%) were found to be screen positive. In total 26 participants tested positive on HR-HPV, and 15 cervical smears returned as abnormal. Figure 1 shows the distribution of the test results of the cervical smears from the women included in the study. In Table 1, the occurrence of HR-HPV and the cytological results per age cohort are presented. Based solely on the current Dutch CSP age-boundaries of 30-60 years, 54 women would be 
Table I Occurrence of HR-HPV and Cytology of the Study Population $(n=74)$

\begin{tabular}{|c|c|c|c|c|c|c|c|c|}
\hline & & \multicolumn{3}{|l|}{ HR-HPV } & \multicolumn{3}{|l|}{ Cytology } & \multirow{3}{*}{$\begin{array}{l}\text { HR-HPV+ and } \\
\text { Abnormal } \\
\text { Smear }\end{array}$} \\
\hline & & \multicolumn{2}{|l|}{ Count } & \multirow{2}{*}{$\begin{array}{l}\text { Percentage } \\
\text { of HR-HPV+ }\end{array}$} & \multicolumn{2}{|l|}{ Count } & \multirow{2}{*}{$\begin{array}{l}\text { Percentage of } \\
\text { Abnormal } \\
\text { Smears }\end{array}$} & \\
\hline & & Negative & Positive & & Normal & Abnormal & & \\
\hline Study population (n) & & 48 & 26 & $35 \%$ & 59 & 15 & $20 \%$ & $12(16)$ \\
\hline \multirow[t]{8}{*}{ Age cohort } & $20-25^{*}$ & I & 6 & $86 \%$ & 4 & 3 & $43 \%$ & $3(43)$ \\
\hline & $25-30 *$ & 10 & 3 & $23 \%$ & 11 & 2 & $15 \%$ & I (8) \\
\hline & $30-35$ & 7 & 4 & $36 \%$ & 8 & 3 & $27 \%$ & $3(27)$ \\
\hline & $35-40$ & 8 & 2 & $20 \%$ & 10 & 0 & $0 \%$ & $0(0)$ \\
\hline & $40-45$ & 8 & 1 & $11 \%$ & 7 & 2 & $22 \%$ & I (II) \\
\hline & $45-50$ & 3 & 4 & $57 \%$ & 6 & 1 & $14 \%$ & I (I4) \\
\hline & $50-55$ & 10 & 3 & $23 \%$ & 13 & 0 & $0 \%$ & $0(0)$ \\
\hline & $55-60$ & I & 3 & $75 \%$ & 0 & 4 & $100 \%$ & $3(75)$ \\
\hline
\end{tabular}

Note: *Women in these age cohorts are not screened by the Dutch CSP.

Abbreviations: HR-HPV, high-risk human papillomavirus; HR-HPV+, high-risk human papillomavirus positive.

eligible for screening, 8 of which were found to be screenpositive.

\section{Prevalence Ratios}

Calculating the PR of the included 54 marginalized women (age boundaries 30-60 years), compared with women screened by the Dutch CSP resulted in a ratio of $4.4(95 \%$ CI 1.9-8.6). This indicates that marginalized women, between the age 30-60 years, have an increased risk of 4.4 being screen-positive in comparison with women screened by the Dutch CSP (Table 2A). The additional calculation, which included the women younger than 30 years of age, provided a PR of 4.8 (95\% CI 2.5-8.3) (Table 2B).

The additional sub-analysis showed that of the 17 undocumented women, 5/17 (29\%) were identified as screen-positives, compared with $7 / 37(8 \%)$ in the documented group.

\section{Invitation Approaches}

The participants of the study were recruited from several locations: 29 participants in homeless shelters, eight participants in a shelter for undocumented women, nine participants in a day shelter for homeless and undocumented people, eight participants in a shelter for sexual human trafficking victims, 15 participants in sex clubs combined with STI screening, and five participants at sex-worker walk-in location combined with STI screening.

Out of the 74 participants, 68 (92\%) women were recruited via the direct invitation approach. The remaining six participants were recruited by an indirect invitation approach. Of the indirect approach, five women were recruited through appointments made by their care providers, and one woman chose to participate after reading the website announcement.

Several women declined to participate in the study. Some were willing to tell their reasons, which mainly met one of the exclusion criteria. In a number of cases, still being virgin was mentioned.

\section{Discussion}

This cross-sectional intervention study, conducted in a large city of the Netherlands, showed that marginalized women have an increased risk on (pre)cancerous cervical abnormalities compared with women screened by the Dutch CSP, with a PR of 4.4. Subsequently, a direct proactive approach was found to be the most effective to 
Table 2 Calculations of the Prevalence Ratios

(A) Prevalence Ratio I. The Study Population (30-60 Years of Age) Compared to Women Screened by the Dutch CSP

\begin{tabular}{|c|c|c|c|c|c|c|}
\hline & & $\begin{array}{l}\text { Prevalence HR-HPV+ and } \\
\text { Abnormal Smear (A) }\end{array}$ & $\begin{array}{l}\text { Number of } \\
\text { Women (B) }\end{array}$ & $\begin{array}{l}\text { Expected } \\
\text { Cases }(\mathrm{AxB})\end{array}$ & $\begin{array}{l}\text { Observed } \\
\text { Cases (C) }\end{array}$ & $\begin{array}{l}\text { Prevalence } \\
\text { Ratio }((C / B) / A)\end{array}$ \\
\hline $\begin{array}{l}\text { Total Women (age } \\
30-60, n=54)\end{array}$ & & 0.034 & 54 & 1.84 & 8 & $\begin{array}{l}4.4(95 \% \mathrm{Cl} \\
1.9-8.6)\end{array}$ \\
\hline \multirow[t]{6}{*}{ Age Category } & $30-35$ & 0.076 & 11 & 0.84 & 3 & \\
\hline & $35-40$ & 0.045 & 10 & 0.45 & 0 & \\
\hline & $40-45$ & 0.032 & 9 & 0.29 & I & \\
\hline & $45-50$ & 0.029 & 7 & 0.20 & I & \\
\hline & $50-55$ & 0.022 & 13 & 0.29 & 0 & \\
\hline & $55-60$ & 0.014 & 4 & 0.06 & 3 & \\
\hline
\end{tabular}

(B) Prevalence Ratio 2. The Study Population (20-60 Years of Age) Compared to Women Screened by the Dutch CSP

\begin{tabular}{|l|l|l|l|l|l|l|}
\hline & & $\begin{array}{l}\text { Prevalence HR-HPV+ and } \\
\text { Abnormal Smear (A) }\end{array}$ & $\begin{array}{l}\text { Number of } \\
\text { Women (B) }\end{array}$ & $\begin{array}{l}\text { Expected } \\
\text { Cases (AxB) }\end{array}$ & $\begin{array}{l}\text { Observed } \\
\text { Cases (C) }\end{array}$ & $\begin{array}{l}\text { Prevalence } \\
\text { Ratio ((C/B)/A) }\end{array}$ \\
\hline $\begin{array}{l}\text { Total Women (age } \\
20-60, n=74)\end{array}$ & 0.034 & 74 & 2.52 & 12 & $4.8(95 \% \mathrm{Cl}$ \\
$2.5-8.3)$
\end{tabular}

Notes: *Women in this age cohort are not screened by the Dutch CSP. Therefore, the prevalence rate for age cohort 20-30 was equated to the screen-positive prevalence rate from age cohort 30-35 years of age.

Abbreviations: CSP, cancer screening programme; HR-HPV+, high-risk human papillomavirus positive.

stimulate screening participation among marginalized women.

The findings of this study are in line with the results of two earlier US-studies among homeless women, showing higher incidence rates of abnormal smears and cervical cancer. $^{11,12}$ This emphasizes on the special needs for screening marginalized women on cervical cancer.

The literature called for new and innovative approaches in order to engage homeless women in cervical screening programs. ${ }^{11}$ Being pro-active and making use of close care providers seemed crucial to engage in addressing this specific population. During the study, peer influence proved invaluable. Several participants became so convinced of the importance of screening they encouraged other women to participate in cervical cancer screening. This mechanism is to be acknowledged as a powerful tool for further enhancing screening uptake among this population and has been described as being effective among other minority groups. ${ }^{18,19}$

Due to several (practical) choices, the study has its limitations. In order to engage with marginalized women, a flexible expert-based approach is essential at the right time and the right place. But, consequently, a direct comparison of invitation methods was not possible. This since not all the approaches were equally suitable at every location. Furthermore, it is not known how many, and more important which women decided to decline participation and what their characteristics were. Reasons mentioned for not participating, collected during the direct approach, varied widely and mostly involved women 


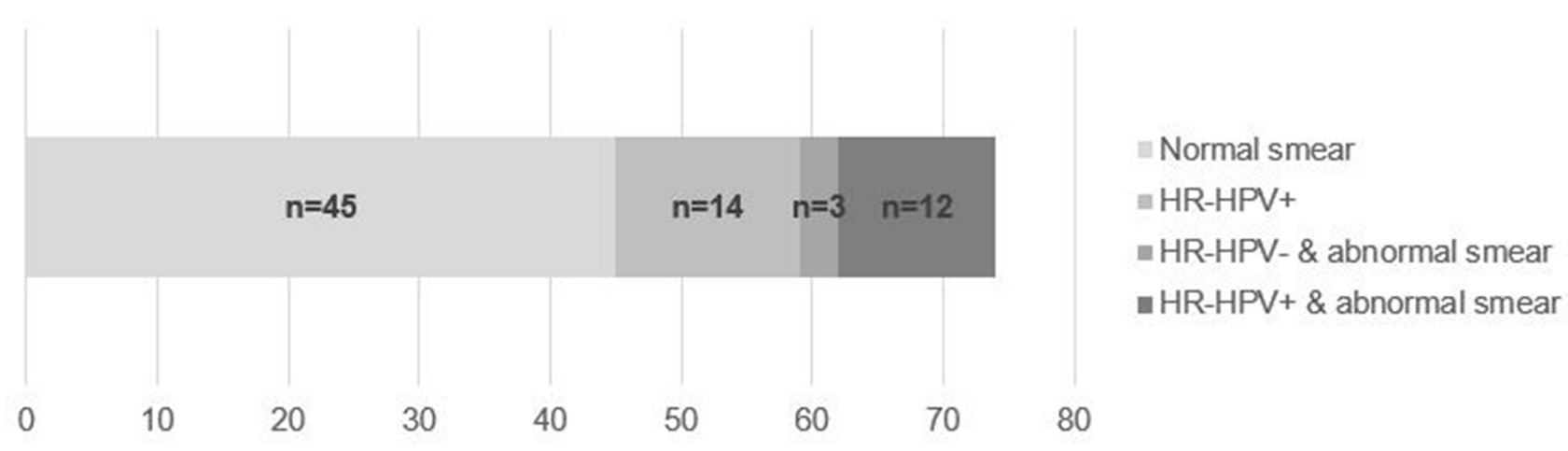

Figure I Distribution test results of the cervical smears. HR-HPV, high-risk human papillomavirus.

who were more hesitant and cautious. A last limitation is that data on the HR-HPV vaccination status of the women was not collected. Participants younger than 21 years of age $(n=2)$ could have received an HR-HPV vaccination; the vaccination program has been in existence in the Netherlands since 2009. In future studies, more participants might be vaccinated for HR-HPV. As this might influence the study results, it should be recorded.

The study included 37 women (50\%) who were eligible for the Dutch CSP but did not participate. This raises the question whether there is a necessity to embark on a tailormade approach for specific high-risk groups within the national CSP. As mentioned in a prior study, involvement of primary care or other relevant care providers for risk groups might enhance screening uptake. ${ }^{7}$

There are several differences between the Dutch cervical CSP and the study. Since special efforts are needed to enhance screening uptake among marginalized women, these differences are highlighted, so further studies can be based on "lessons learned". Box 1 summarizes suggestions for implementing a cervical screening program for marginalized women.

Box I Recommendations for Implementing a Cervical Screening Program for Marginalized Women

I. Be pro-active as care provider;

2. Provide the cervical smear at the locations where the women work, reside or receive care;

3. Use a trusted care provider on the location for recruitment and the introduction of the program;

4. Use female medical teams;

5. Involve peers: give them a role in educating and raising awareness;

6. Consider screening from a younger age onward, starting at the age of 25 is recommended;

7. Make sure follow-up is guaranteed and explore regionally which organizations can cooperate.
One of the aims of the study was to remove as many of the access barriers as possible. Marginalized women were invited in a pro-active individual manner, without the necessity of a health insurance. The cervical smear was performed directly at the locations where these women would already be present to work, reside or receive care. Engagement and participation based on trust was shown to be crucial in the study, especially as many women mentioned a history of sexual trauma. The topic of cervical screening was introduced by a close care provider from the location, and this care provider introduced the women to the medical team. The medical team was all female and invested time in gaining the trust of the participant before taking the cervical smear. In the Dutch CSP, the smear is performed by a person's GP. The studied population, however, often does not have guaranteed access to the typically Dutch GP-oriented healthcare system. Therefore, an approach based on creating a safe environment seemed an effective alternative. The study shows that involving peers in educating and raising awareness among the target population will most definitely lead to higher participation rates. The tailor-made approach for engaging this population in cervical cancer screening is very timeconsuming and greatly depends on the availability of a network and the setting, which has proven the major drawback of this approach.

The age boundaries of cervical CSPs do differ between countries, and are under constant review. ${ }^{14,20,21}$ Because of the assumption that marginalized women are being exposed to the risk factors for cervical cancer earlier in life, leading to cervical cell abnormalities at a younger age, the age limits for eligible women in the study were extended to the age of 20 , instead of 30 . A second PR calculation included these younger women and, before calculation, the screen-positive prevalence rate was equated to the prevalence rate from age cohort $30-35$ years of 
age. This since the Dutch CSP is not screening women between 20 and 30 years of age, and therefore no agespecific prevalence rates are known. This is most probably an underestimation. HR-HPV infections will be more prevalent among younger women but will most often be transient, and thus will not progress into cervical lesions. HR-HPV testing for women younger than 25 years has a low specificity and creates a risk of over-referral and overtreatment. When screening for (pre)cancerous cervical abnormalities in women below the age of 25 , cytology should be the primary screening method. ${ }^{22}$ However, including these younger women in the PR calculation, does show an increase of the PR-ratio. This suggests inclusion of women between the age of 25-30 in a highrisk group - such as marginalized women - with an early exposure to HPV, is justifiable and advisable.

Clear arrangements were made with the participating women concerning follow-up and how these results would be reported back. In total 12 participants needed referral to a gynecologist, which eventually were all managed successfully. Nevertheless, it was crucial to have a back-up municipal safety-net team. One of the 12 referred participants missed out on the second appointment with the gynecologist, due to a transfer to a safe house in another region. She was traced and referred to a gynecologist in the other region. Another referred participant did not make an appointment with the gynecologist due to an emergency admission in a detox facility. After being traced, she needed a new referral. Tracing all the participants who needed a repeat cervical smear after 6 months as part of the follow-up proved the most challenging. All women could be traced through the public health safetynet team. Future implementation studies should further explore these challenges regarding the follow-up, and most ideally tackle these logistical problems beforehand.

The study included undocumented and European (nonDutch) women, who are unable to partake in the Dutch cervical CSP. The reason for including these women, was that they are assigned to the care of streetdoctors, and they also face a high prevalence of risk factors concerning the development of cervical cancer. Without any possibility to return to their homeland for treatment, they will receive the treatment in the Netherlands, with all the attendant costs included. This is of high importance because the findings suggest that undocumented women also have a high risk on (pre)cancerous cervical abnormalities. The number of participants in the study is too low for definitive conclusions, but more research in this specific subpopulation is firmly recommended.

\section{Conclusion}

The current national population-based cancer screening program for cervical cancer is largely missing out on marginalized women. In view of their increased risk, efforts should be made to enhance screening uptake among marginalized women at the cervical CSP. A tailor-made, direct and proactive invitation approach will most probably be successful to involve marginalized women in cervical screening. In the discussion suggestions and recommendations are offered for future studies. Both researchers and policymakers are invited to use this study for optimizing the current cervical CSPs.

\section{Acknowledgments}

The authors wish to thank all partners who welcomed the medical team with trust and expertise on how to engage the study population. Many acknowledgements to Annelies van Vliet-Klerk from the Erasmus Medical Center for coordinating the liquid-based cytology sampling, and to all members of the cytology team for analyzing the cervical samples. Appreciation for Stichting Bevolkingsonderzoek Zuid-West for covering a part of the costs and by supporting this research. Gratitude to the Netherlands Streetdoctors Group for solving the financial puzzle, regarding the cytology sampling.

\section{Disclosure}

The authors report no potential conflicts of interest with respect to the research, authorship, and/or publication of this article.

The authors received non-financial support from the Netherlands Streetdoctors Group, non-financial support from Erasmus Medical Center, and non-financial support from Stichting Bevolkingsonderzoek Zuid-West.

\section{References}

1. Ferlay J, Ervik M, Lam F, et al. International agency for research on cancer. global cancer observatory: cancer today; 2019. Available from: https://gco.iarc.fr/today. Accessed May 17, 2021.

2. Dunne EF, Unger ER, Sternberg $M$, et al. Prevalence of HPV0-o infection among females in the United States. JAMA. 2007;297(8):813-819. doi:10.1001/jama.297.8.813

3. Stumbar SE, Stevens M, Feld Z. Cervical cancer and its precursors: a preventative approach to screening, diagnosis, and management. Prim Care. 2019;46(1):117-134. doi:10.1016/j.pop.2018.10.011

4. Bevolkingsonderzoek Nederland. Cervical Cancer Screening. Available from: https://www.bevolkingsonderzoeknederland.nl/en/pro fessionals/bevolkingsonderzoek-baarmoederhalskanker. Accessed May 25, 2021.

5. Rijksinstituut voor Volksgezondheid en Milieu. Monitor van het Bevolkingsonderzoek Baarmoederhalskanker 2018. Available from: https://www.rivm.nl/documenten/monitor-bevolkingsonderzoek-baar moederhalskanker-2018. Accessed May 25, 2021. 
6. Haaren K. Baarmoederhalskanker, Bevolkingsonderzoek En Diagnostiek. Nederlands Huisartsen Genootschap; 2016.

7. Bongaerts TH, Büchner FL, Middelkoop BJ, Guicherit OR, Numans ME. Determinants of (non-)attendance at the Dutch cancer screening programs: a systematic review. $J$ Med Screen. 2019;27:969141319887996. doi:10.1177/0969141319887996

8. Akinlotan M, Bolin JN, Helduser J, Ojinnaka C, Lichorad A, McClellan D. Cervical cancer screening barriers and risk factor knowledge among uninsured women. J Community Health. 2017;42 (4):770-778. doi:10.1007/s10900-017-0316-9

9. Weinreb L, Goldberg R, Lessard D. Pap smear testing among homeless and very low-income housed mothers. J Health Care Poor Underserved. 2002;13(2):141-150. doi:10.1353/hpu.2010.0528

10. Mings J, Soto Mas F. Barriers to pap smear among homeless women at albuquerque healthcare for the homeless. J Community Health. 2019;44(6):1185-1192. doi:10.1007/s10900-019-00704-y

11. Bharel M, Casey C, Wittenberg E. Disparities in cancer screening: acceptance of Pap smears among homeless women. J Womens Health. 2009;18(12):2011-2016. doi:10.1089/jwh.2008.1111

12. Baggett TP, Chang Y, Porneala BC, Bharel M, Singer DE, Rigotti NA. Disparities in cancer incidence, stage, and mortality at Boston health care for the homeless program. Am J Prev Med. 2015;49(5):694-702. doi:10.1016/j.amepre.2015.03.038

13. Denton KJ, Herbert A, Turnbull LS, et al. The revised BSCC terminology for abnormal cervical cytology. Cytopathology. 2008;19 (3):137-157. doi:10.1111/j.1365-2303.2008.00585.x

14. Herbert A, Bergeron $\mathrm{C}$, Wiener $\mathrm{H}$, et al. European guidelines for quality assurance in cervical cancer screening: recommendations for cervical cytology terminology. Cytopathology. 2007;18(4):213-219. doi:10.1111/j.1365-2303.2007.00469.x
15. Stichting Bevolkingsonderzoek Zuid-West. Jaarverslag; 2018. Available from: https://www.bevolkingsonderzoeknederland.nl/ media/1307/jaarverslag-2018-bozw.pdf. Accessed May 17, 2021.

16. Clinical.com. Sample size calculator; 2021. Available from: https:// clincalc.com/stats/samplesize.aspx. Accessed May 17, 2021.

17. Rijksinstituut voor Volksgezondheid en Milieu. Monitor bevolkingsonderzoek baarmoederhalskanke. 2018.

18. Escribà-Agüir V, Rodriguez-Gomez M, Ruiz-Perez I. Effectiveness of patient-targeted interventions to promote cancer screening among ethnic minorities: a systematic review. Cancer Epidemiol. 2016;44:22-39. doi:10.1016/j.canep.2016.07.009

19. Thulien NS. Innovative approaches to cervical cancer screening for sex trade workers: an international scoping review. J Obstetr Gynaecol Can. 2014;36(3):231-239. doi:10.1016/S1701-2163(15) 30631-9

20. Vesco KK, Whitlock EP, Eder M, Burda BU, Senger CA, Lutz K. Risk factors and other epidemiologic considerations for cervical cancer screening: a narrative review for the U.S. Preventive Services Task Force. Ann Intern Med. 2011;155(10):698-705, w216. doi:10.7326/0003-4819-155-10-201111150-00377

21. Chrysostomou AC, Stylianou DC, Constantinidou A, Kostrikis LG. Cervical cancer screening programs in Europe: the transition towards HPV vaccination and population-based HPV testing. Viruses. 2018;10(12):729. doi:10.3390/v10120729

22. World Health Organization. Reproductive Health, World Health Organization, World Health Organization. Chronic Diseases, Health Promotion. Comprehensive Cervical Cancer Control: A Guide to Essential Practice. World Health Organization; 2006.

\section{Publish your work in this journal}

The International Journal of Women's Health is an international, peerreviewed open-access journal publishing original research, reports, editorials, reviews and commentaries on all aspects of women's healthcare including gynecology, obstetrics, and breast cancer. The manuscript management system is completely online and includes a very quick and fair peer-review system, which is all easy to use. Visit http://www.dovepress.com/testimonials.php to read real quotes from published authors. 